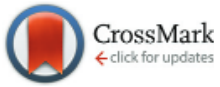

Cite this: Org. Biomol. Chem., 2015, 13, 447

Received 7th October 2014, Accepted 16th October 2014

DOI: $10.1039 / c 4 o b 02138 j$

www.rsc.org/obc

\section{Efficient merging of copper and photoredox catalysis for the asymmetric cross-dehydrogenative-coupling of alkynes and tetrahydroisoquinolines $\uparrow$}

\author{
Inna Perepichka, Soumen Kundu, Zoë Hearne and Chao-Jun Li*
}

Selective cross-coupling reactions for $\mathrm{C}-\mathrm{C}$ bond formation via direct activation of $\mathrm{C}-\mathrm{H}$ bonds under oxidizing conditions (cross-dehydrogenative coupling, CDC) provide an atom economical and sustainable alternative to classical cross-coupling protocols. ${ }^{1-8}$ In the last decade, CDC methodologies formulated by us ${ }^{9-16}$ and further developed by others ${ }^{17-22}$ have provided a plethora of novel single-step routes to create $\mathrm{C}-\mathrm{C}$ bonds, thus responding to the ever-growing demand for 'green' innovation in chemical design and synthesis. We have previously reported the CDC reaction for alkynylation of tertiary amines, whereby an $\mathrm{sp}^{3} \mathrm{C}-\mathrm{H}$ bond $\alpha$ to a tertiary nitrogen atom, and an sp $\mathrm{C}-\mathrm{H}$ bond of a terminal alkyne were simultaneously activated by a $\mathrm{CuBr} /{ }^{t} \mathrm{BuOOH}$ catalyzed process. ${ }^{9}$ This provides access to propargylic amines, which are valuable synthetic intermediates. ${ }^{23-26}$ An enantioselective variation of this reaction was realized in the presence of a catalytic bis(oxazoline)-based PyBox chiral ligand (L1, Fig. 1), ${ }^{27,28}$ in which direct activation of the prochiral $\mathrm{CH}_{2}$ group in $\mathrm{N}$-aryl-tetrahydroisoquinolines resulted in the synthesis of biologically active chiral C-1 substituted tetrahydroisoquinoline alkaloid derivatives (Scheme 1A). This methodology has advantages over contemporary methods that require pre-synthesis of imine or iminium substrates. $^{29} \mathrm{Yu}$ et al. performed this reaction under highspeed ball-milling under solvent free conditions, using recoverable copper balls with the PyBox ligand and stoichiometric 2,3-dichloro-5,6-dicyanobenzoquinone as an oxidant to synthesize optically active 1-alkynyl tetrahydroisoquinoline derivatives (Scheme 1B). ${ }^{30}$ However, in both aforementioned cases, the optically active products were formed in only moderate yields $^{28,30}$ and enantiomeric excesses (Scheme $1 \mathrm{~A}$ and $1 \mathrm{~B}$ ). ${ }^{28,30}$

Department of Chemistry, McGill University, 801 Sherbrooke St. West, Montreal, Quebec H3A OB8, Canada. E-mail: cj.li@mcgill.ca

$\dagger$ Electronic supplementary information (ESI) available. See DOI: 10.1039/ c4ob02138j

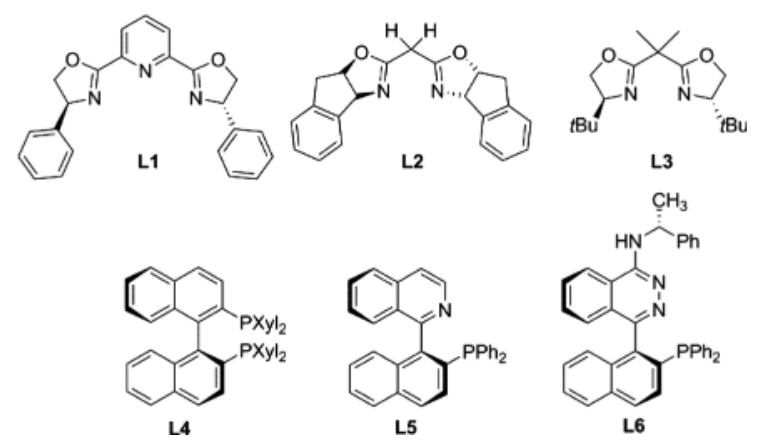

Fig. 1 Chiral ligands (L) used. L1 $=(S)$-PyBox, L2 $=(S, S-R, R)$-Box1, $\mathrm{L3}=(R)$-Box2, L4 $=(R)$-XyIBINAP, L5 $=(R)$-QUINAP, L6 $=(R, R)-N-$ PINAP.

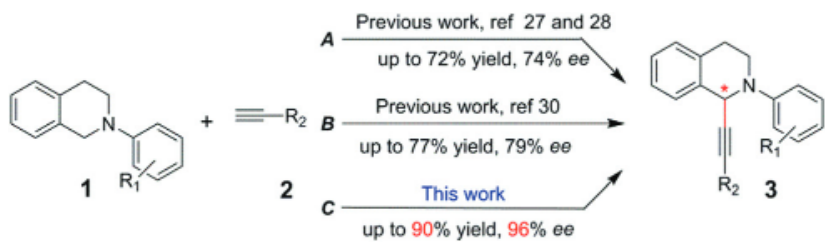

Scheme 1 Enantioselective alkynylation of $N$-aryl-tetrahydroisoquinoline.

This motivated us to develop a novel concept to overcome these challenges.

Reaction temperature has a profound impact on the enantioselectivity of stereoselective reactions; lowering the temperature often results in better selectivity. ${ }^{31}$ However, while our previously reported CDC methodology is effective at $50^{\circ} \mathrm{C}$ to produce optically active compounds, the desired coupling products are not observed at lower temperatures. ${ }^{27}$

On the other hand, following MacMillan and co-workers' ground-breaking studies on photoredox organic reactions using visible light, ${ }^{32,33}$ which have since been developed by 
Stephenson, ${ }^{34,35}$ Sanford, ${ }^{36,37}$ Yoon $^{38-40}$ and others, ${ }^{41}$ metal ( $\mathrm{Ru}$ and $\mathrm{Ir}$ ) polypyridyl complexes ${ }^{41-44}$ and metal-free organic dye-sensitizers ${ }^{45-47}$ have been used to substitute $N$-aryl-tetrahydroisoquinolines at the $\mathrm{C} 1$ position with a variety of nucleophiles (cyanide, nitroalkane, trifluoromethyl, dialkyl malonates, dialkyl phosphonates, terminal alkynes etc.). The most appealing feature of photoredox catalysis, for our current objectives, is the requirement of very mild conditions (room and low temperature), thereby providing great opportunities for asymmetric synthesis.

Herein, we report a highly efficient catalytic asymmetric alkynylation of prochiral $\mathrm{CH}_{2}$ groups in $\mathrm{N}$-aryl-tetrahydroisoquinolines by combining a photoredox process with a chiral copper catalyst. The reaction produces optically active 1 -alkynyl tetrahydroisoquinoline derivatives in the highest yield and enantiomeric excess reported so far (Scheme 1), using a photocatalyst $\left(\left[\mathrm{Ru}(\mathrm{bpy})_{3}\right]\left(\mathrm{PF}_{6}\right)_{2}\right.$ or $\left.\left[\operatorname{Ir}(\mathrm{ppy})_{2}(\mathrm{~d} t \mathrm{bbpy})\right] \mathrm{PF}_{6}\right)$ under visible light irradiation together with the $\mathrm{CuBr} / \mathrm{chiral}$ ligand (L, Fig. 1) and benzoyl peroxide as the terminal oxidant. Such merging of a photocatalyst and a metal catalyst (or organocatalyst) is an attractive alternative to traditional cross-coupling reactions; it produces valuable fine chemicals that cannot be accessed by the independent use of these catalysts. ${ }^{41,48,49}$ Enantioselective variation of such a dual catalysis approach is still very rare. ${ }^{49,50}$

We started our investigation of the photocatalyzed enantioselective oxidative CDC reaction between an alkyne and a tertiary amine using prototype substrates $\mathrm{N}$-phenyl-tetrahydroisoquinoline and phenylacetylene, and employing the photosensitizer $\left[\mathrm{Ru}(\mathrm{bpy})_{3}\right]\left(\mathrm{PF}_{6}\right)_{2}{ }^{38}$ in $\mathrm{CH}_{3} \mathrm{CN}$ under visible light irradiation, in the presence of CuOTf, ${ }^{t} \mathrm{BuOOH}$, and bisoxazoline chiral ligand $\mathbf{L 1}$ at room temperature (RT). The desired product was not observed under these conditions after $24 \mathrm{~h}$. Changing the oxidant from ${ }^{t} \mathrm{BuOOH}$ to benzoyl peroxide, $(\mathrm{BzO})_{2}$, allowed the alkynylation reaction to proceed with good yield (70\%), but poor enantioselectivity (ee $8 \%$, Table 1 , entry 1). Variation of the chiral ligand (L2-L4) and copper salt (CuOTf and $\mathrm{CuCl}$, Table 1 , entries 2-5) resulted in a slight improvement in enantioselectivity ( $24 \%$ ee, Table 1 , entry $5, \mathbf{L} 4$ and $\mathrm{CuCl}$ ). Acetonitrile is a coordinating solvent, ${ }^{51}$ and as such can hinder the chiral induction of ligands $(\mathbf{L}){ }^{52}$ Our efforts to screen less coordinating solvents were hampered by the low solubility of $\left[\mathrm{Ru}(\mathrm{bpy})_{3}\right]\left(\mathrm{PF}_{6}\right)_{2}$ in common organic solvents. Hence, we replaced $\left[\mathrm{Ru}(\mathrm{bpy})_{3}\right]\left(\mathrm{PF}_{6}\right)_{2}$ by the more potent photoredox catalyst $\left[\operatorname{Ir}(\mathrm{ppy})_{2}(\mathrm{dtbbpy})\right] \mathrm{PF}_{6},{ }^{42}$ which is highly soluble in most organic solvents (Table 1, entries 6-17). Chiral ligand $\mathbf{L} 5$ provided good enantioselectivities (ee 79 and $86 \%$, Table 1, entries 9 and 11, respectively) at room temperature in THF using copper(I) catalysts $\mathrm{CuBr}$ and $\mathrm{CuCl}$ (Table 1, entries 9 and 11). However, these reactions resulted in only moderate yields of the desired products ( 41 and $30 \%$, Table 1 , entries 9 and 11 , respectively) and low overall conversion of the starting material (ca. 50\%). In $\mathrm{CH}_{3} \mathrm{CN}$ with a $\mathrm{CuBr}$ catalyst the reaction yield considerably improved (87\%, with $100 \%$ conversion) with concomitant lowering of the enantioselectivity (ee $70 \%$, Table 1, entry 10). Other combinations of chiral ligands (L),
Table 1 Eff ect of copper salt and chiral ligand (L: Fig. 1) on the enantioselectivity of coupling of $N$-phenyl-tetrahydroisoquinoline with phenylacetylene at $\mathrm{RT}^{\mathrm{a}}$

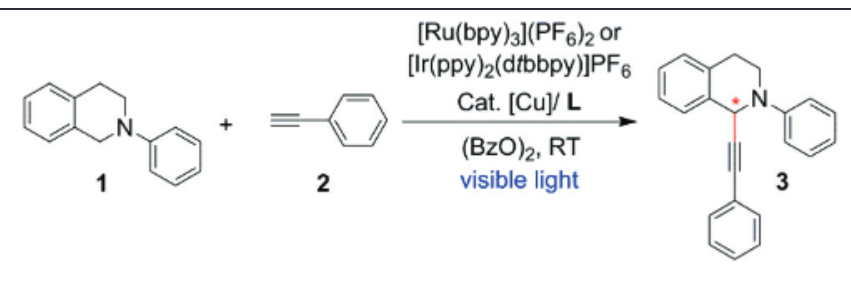

\begin{tabular}{|c|c|c|c|c|}
\hline Entry & Cat. $[\mathrm{Cu}]$ & $\mathbf{L}$ & Solvent & $\mathrm{ee}^{d}(\%)$ \\
\hline $1^{b}$ & CuOTf & L1 & $\mathrm{CH}_{3} \mathrm{CN}$ & 8 \\
\hline $2^{b}$ & CuOTf & L2 & $\mathrm{CH}_{3} \mathrm{CN}$ & 4 \\
\hline $3^{b}$ & CuOTf & L3 & $\mathrm{CH}_{3} \mathrm{CN}$ & 2 \\
\hline $4^{b}$ & CuOTf & L4 & $\mathrm{CH}_{3} \mathrm{CN}$ & 5 \\
\hline $5^{b}$ & $\mathrm{CuCl}$ & L4 & $\mathrm{CH}_{3} \mathrm{CN}$ & 24 \\
\hline $6^{c}$ & $\mathrm{CuCl}$ & L4 & DCM & 1 \\
\hline $7^{c}$ & $\mathrm{CuCl}$ & L4 & THF & 34 \\
\hline $8^{c}$ & $\mathrm{CuCl}$ & L5 & $\mathrm{CH}_{3} \mathrm{CN}$ & 22 \\
\hline $9^{c}$ & $\mathrm{CuCl}$ & L5 & THF & $79(41)^{e}$ \\
\hline $10^{c}$ & $\mathrm{CuBr}$ & L5 & $\mathrm{CH}_{3} \mathrm{CN}$ & $70(87)^{e}$ \\
\hline $11^{c}$ & $\mathrm{CuBr}$ & L5 & THF & $86(30)^{e}$ \\
\hline $12^{c}$ & $\mathrm{CuBr}_{2}$ & L5 & THF & 17 \\
\hline $13^{c}$ & $\mathrm{CuI}$ & L5 & THF & 27 \\
\hline $14^{c}$ & $\mathrm{CuBr}$ & L6 & THF & 7 \\
\hline $15^{c}$ & $\mathrm{CuBr}$ & L6 & Toluene & 8 \\
\hline $16^{c}$ & $\mathrm{CuBr}$ & L6 & DCM & 2 \\
\hline $17^{c}$ & $\mathrm{CuBr}$ & L6 & $\mathrm{CH}_{3} \mathrm{CN}$ & 9 \\
\hline
\end{tabular}

${ }^{a}$ Conditions: $0.1 \mathrm{mmol} \mathrm{N}$-phenyl-tetrahydroisoquinoline, $0.1 \mathrm{mmol}$ phenylacetylene, $10 \mathrm{~mol} \%$ copper salt, $15 \mathrm{~mol} \%$ chiral ligand (L), $1 \mathrm{~mol} \%\left[\mathrm{Ru}(\mathrm{bpy})_{3}\right]\left(\mathrm{PF}_{6}\right)_{2}$ (entries 1-5). ${ }^{b}\left[\operatorname{Ir}(\mathrm{ppy})_{2}(\mathrm{dtbbpy})\right] \mathrm{PF}_{6}$ (entries $6-17) .{ }^{c} 0.12 \mathrm{mmol}(\mathrm{BzO})_{2}, 20 \mathrm{~h}$ reaction time, RT. ${ }^{d}$ The ee values were determined by HPLC using a Chiralcel OD-H column and 4:96 hexane-isopropanol as an eluent (ESI). ${ }^{e}$ The yields in parentheses were calculated by the ${ }^{1} \mathrm{H}$ NMR integration method using $\mathrm{CH}_{3} \mathrm{NO}_{2}$ as an internal standard (ESI).

copper(I/II) salts, and solvents were ineffective in increasing enantioselectivities (Table 1, entries 6-8 and 12-17). The reaction did not proceed in the absence of copper salt (ESI $\dagger$ ). The product yield was drastically reduced when either the photosensitizer was omitted ( $24 \%$ yield, ESI $\dagger$ ) or the reaction was conducted in the dark ( $16 \%$ yield, ESI $\dagger$ ). No improvement in the enantioselectivity (ee) or product yield was observed upon increasing the amounts of phenylacetylene or chiral ligand $\mathbf{L}$ (ESI†).

Finally, the effect of temperature and solvent combination on the reaction enantioselectivity (ee) and yield were evaluated (Table 2). In THF and $\mathrm{CH}_{3} \mathrm{CN}$, predictably, the enantioselectivity (ee) of the reactions systematically increased with lowering of the reaction temperature (Table 2, entries 1-6). At $-20{ }^{\circ} \mathrm{C}$, the reaction in THF provided the best enantioselectivity ( $97 \%$ ee) but the lowest yield (46\%), whereas high yield (80\%) but somewhat inferior enantioselectivity (ee 93\%) was obtained in $\mathrm{CH}_{3} \mathrm{CN}$ (Table 2, entries 3 and 6). A compromise was achieved using a solvent mixture of THF and $\mathrm{CH}_{3} \mathrm{CN}$ $(1: 1)$ at $-20^{\circ} \mathrm{C}$ which resulted in $94 \%$ enantioselectivity and $64 \%$ yield (Table 2 , entry 8 ). In the same solvent mixture, a reaction at $-40{ }^{\circ} \mathrm{C}$ resulted in further improvement of the enantioselectivity (ee $96 \%$, Table 2, entry 9) and yield (75\%, Table 2, 
Table 2 Eff ect of the solvent and temperature on the enantioselectivity of coupling of $\mathrm{N}$-phenyl-tetrahydroisoquinoline with phenylacetylene

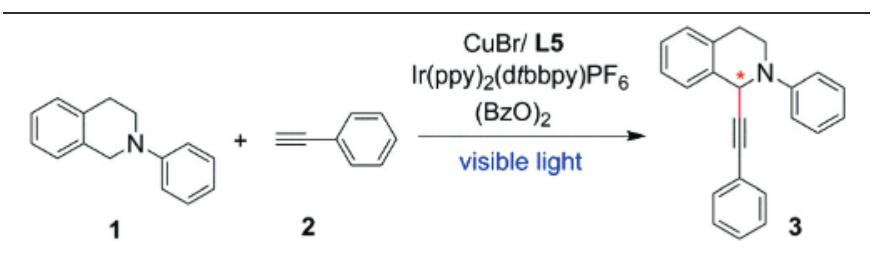

\begin{tabular}{llrl}
\hline Entry $^{a}$ & Solvent & $T /{ }^{\circ} \mathrm{C}$ & $\mathrm{ee}^{b} / \%$ \\
\hline 1 & THF & 22 & 86 \\
2 & & 4 & 92 \\
3 & & -20 & $97(46)^{c}$ \\
4 & $\mathrm{CH}_{3} \mathrm{CN}$ & 22 & 70 \\
5 & & 4 & 88 \\
6 & & -20 & $93(80)^{c}$ \\
7 & $\mathrm{THF}^{c} \mathrm{CH}_{3} \mathrm{CN}(1: 1)$ & 22 & $79(75)^{c}$ \\
8 & & -20 & $94(64)^{c}$ \\
9 & & -40 & $96(75)^{c}$
\end{tabular}

${ }^{a}$ Conditions: $\quad 0.1 \mathrm{mmol}$ tetrahydroisoquinoline, $0.1 \mathrm{mmol}$ phenylacetylene, $10 \mathrm{~mol} \% \mathrm{CuBr}, 15 \mathrm{~mol} \% \quad \mathbf{L 5}, 1 \mathrm{~mol} \%\left[\operatorname{Ir}(\mathrm{ppy})_{2^{-}}\right.$ $(\mathrm{d} t \mathrm{bbpy})] \mathrm{PF}_{6}$, and $0.12 \mathrm{mmol}(\mathrm{BzO})_{2}$, reaction times and temperatures: $20 \mathrm{~h} / 22{ }^{\circ} \mathrm{C}$ (RT), $46 \mathrm{~h} / 4{ }^{\circ} \mathrm{C}, 48 \mathrm{~h} /-20{ }^{\circ} \mathrm{C}, 90 \mathrm{~h} /-40{ }^{\circ} \mathrm{C} .{ }^{b} \mathrm{The}$ enantiomeric excess was determined as described in Table 1 (ESI).

${ }^{c}$ In parentheses, the yield was calculated as described in Table 1 (ESI).

entry 9). Although in this case the reaction time was twice as long ( $4 \mathrm{~d}$ ) compared to that at $-20^{\circ} \mathrm{C}$.

With the optimized conditions in hand we investigated the effect that substituents on $N$-phenyl-tetrahydroisoquinoline (1, Table 3 ) and terminal alkyne (2, Table 3 ) had on the reaction enantioselectivity and yield (Table 3 ). To expedite the substrate scope analysis reactions were performed at $-20{ }^{\circ} \mathrm{C}$ (for most substrates, Table 3), to achieve a compromise between reaction time and enantioselectivity. Terminal alkynes with $n$-alkyl or aryl substituents all afforded the corresponding products (3, Table 3) in moderate to excellent yields (up to $90 \%$ ) with high enantioselectivities (up to 94\%). Moreover, functionalized aliphatic alkynes, such as TMS-acetylene (Table 3, entry 6), also produced the desired product (3f, Table 3) with good enantioselectivity and acceptable yield. The previously reported non-photoredox procedures either did not include this alkyne as the substrate ${ }^{28,30}$ or produced the chiral product (3f, TMS) in very low yield (11\%) and enantiomeric excess $(30 \%) .{ }^{28}$ Thus, this combination of photoredox catalysis and chiral metal catalysis further provides opportunities for attractive synthetic transformations tolerant of the TMS functionality. ${ }^{28,30}$ Functional group variation of the alkyne had a moderate impact on the enantioselectivity (except for TMS, Table 3, entries 1-6) but a more significant effect on reaction yields. Aliphatic alkynes resulted in chiral products with lower yields (Table 3 , entries $4-6,9$, and 11) compared to aromatic alkynes. Lastly, we investigated the influence of substituents on the phenyl ring of the tetrahydroisoquinoline substrate (Table 3). Substituents at the meta- (OMe) and para- (Me) position had a minor influence on the enantioselectivities of the reaction (Table 3). However, $\mathrm{N}$-(4-bromophenyl)-tetrahydroisoquinoline consistently afforded lower yields with different
Table 3 Enantioselectivity of coupling between tetrahydroisoquinolines with terminal alkynes in the presence of a photocatalyst and visible light

\begin{tabular}{|c|c|c|c|c|c|}
\hline & $1^{R_{1}^{c}}$ & $=\mathrm{R}_{2}$ & $\begin{array}{l}\mathrm{CuBr} / \mathrm{L5} \\
\mathrm{y})_{2}(\mathrm{~d} t \mathrm{bbpy}) \mathrm{PF}_{6} \\
(\mathrm{BzO})_{2} \\
-20^{\circ} \mathrm{C}, 2 \mathrm{~d} \\
\mathrm{~F} / \mathrm{CH}_{3} \mathrm{CN}(1: 1) \\
\text { visible light }\end{array}$ & $\mathrm{R}_{2}$ & \\
\hline Entry $^{a}$ & $\mathrm{R}_{1}$ & $\mathrm{R}_{2}$ & Compound & Yield $^{c}(\%)$ & $\mathrm{ee}^{d} / \%$ \\
\hline & $\mathrm{H}$ & $\mathrm{Ph}$ & $3 a$ & 64 & 94 \\
\hline & $\mathrm{H}$ & $4-\mathrm{MeOC}_{6} \mathrm{H}_{4}$ & $3 \mathbf{b}$ & 67 & 87 \\
\hline 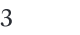 & $\mathrm{H}$ & $4-\mathrm{BrC}_{6} \mathrm{H}_{4}$ & $3 c$ & 72 & 94 \\
\hline & $\mathrm{H}$ & $n$-Bu & $3 d$ & 48 & 87 \\
\hline 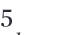 & $\mathrm{H}$ & $n$-Octyl & $3 e$ & 57 & 82 \\
\hline $6^{b}$ & $\mathrm{H}$ & TMS & $3 f$ & 40 & 60 \\
\hline & $\mathrm{H}$ & $4-\mathrm{PhC}_{6} \mathrm{H}_{4}$ & $3 g$ & 46 & 84 \\
\hline 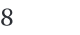 & 3-OMe & $\mathrm{Ph}$ & $3 \mathbf{h}$ & 55 & 94 \\
\hline 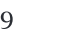 & 3-OMe & $n-\mathrm{Bu}$ & $3 \mathbf{i}$ & 47 & 90 \\
\hline 10 & $4-\mathrm{Me}$ & $4-\mathrm{MeOC}_{6} \mathrm{H}_{4}$ & $3 \mathbf{j}$ & 90 & 94 \\
\hline 11 & $4-\mathrm{Br}$ & $n$-Bu & $3 \mathbf{k}$ & 20 & 87 \\
\hline 12 & $4-\mathrm{Br}$ & $4-\mathrm{MeOC}_{6} \mathrm{H}_{4}$ & 31 & 30 & 81 \\
\hline $13^{e}$ & 2-OMe & $\mathrm{Ph}$ & $3 m$ & 80 & 80 \\
\hline
\end{tabular}

${ }^{a}$ Conditions: $0.1 \mathrm{mmol}$ tetrahydroisoquinoline, $0.15 \mathrm{mmol}$ alkyne, $10 \mathrm{~mol} \% \mathrm{CuBr}, 15 \mathrm{~mol} \%$ L5, $1 \mathrm{~mol} \%\left[\operatorname{Ir}(\mathrm{ppy})_{2}(\mathrm{~d} t \mathrm{bbpy})\right] \mathrm{PF}_{6}$ and $0.12 \mathrm{mmol}(\mathrm{BzO})_{2}$, visible light, reaction time 2 days at $-20{ }^{\circ} \mathrm{C}$. ${ }^{b}$ The reaction time of 2 days at $4{ }^{\circ} \mathrm{C}$. ${ }^{c}$ The yields are based on tetrahydroisoquinoline and were calculated as described in Table 1 (ESI). ${ }^{d}$ Determined as described in Table 1 (ESI). ${ }^{e} \mathrm{O}_{2}$ as a terminal oxidant in place of $(\mathrm{BzO})_{2}$. The reaction time of 2 days at $4{ }^{\circ} \mathrm{C}$. The yield was calculated based on conversion of 1 (ESI).

alkynes (Table 3, entries 11 and 12). $N$-(2-Methoxyphenyl)-tetrahydroisoquinoline was unstable under the oxidative reaction conditions $^{30,41,53}$ and instead of the desired CDC product produced the corresponding $\mathrm{N}$-(2-methoxy)-tetrahydroisoquinoline amide (ESI $\dagger){ }^{53}$ Gratifyingly, we found that changing the terminal oxidant from $(\mathrm{BzO})_{2}$ to $\mathrm{O}_{2}$ (ESI $\dagger$ ) (Table 3, entry 13) resulted in the formation of the desired product $(3 \mathrm{~m})$ in good yield and enantiomeric excess.

Based on the well-established mechanism of photocatalyst $\mathrm{Ru}(\mathrm{bpy})_{3} / \operatorname{Ir}(\mathrm{ppy})_{2}\left(\mathrm{~d} t\right.$ bbpy) mediated organic reactions ${ }^{32,38,40-42}$ and CDC reactions involving $\mathrm{N}$-aryl-tetrahydroisoquinoline, ${ }^{9,27,28,54}$ we propose the following coupled pathways for product formation. In the photoredox catalytic cycle, upon interacting with visible light $\mathrm{Ir}^{\mathrm{III}}$ is transformed into the redoxactive photoexcited state $\operatorname{Ir}^{\mathrm{III}_{*}}$, before being reductively quenched by single-electron-transfer (SET) from the nitrogen of $N$-aryl-tetrahydroisoquinoline (1a, Scheme 2) to generate $\mathrm{Ir}^{\mathrm{II}}$ and an amine cation radical intermediate (6a, Scheme 2). Ir $^{\mathrm{II}}$ is re-oxidized to $\mathrm{Ir}^{\mathrm{III}}$ by SET reduction of $(\mathrm{BzO})_{2}$ to the $\mathrm{BzO}^{-}$ anion and $\mathrm{BzO}^{\circ}$ radical. ${ }^{55}$ This benzoyloxy radical abstracts the benzylic hydrogen of $\mathbf{6 a}$ to produce the reactive iminium ion intermediate (7a, Scheme 2). Deprotonation of $\alpha \mathrm{C}-\mathrm{H}$ in $\mathbf{6 a}$, followed by 1 -e oxidation of the generated $\alpha$-amino radical can also produce $7 a^{41}$ The experimental data do not allow us to distinguish between these possibilities. In the $\mathrm{CuBr}$ mediated catalytic cycle, QUINAP (L5) binds to copper to form a chiral Cu-QUINAP (Cu-1) complex, ${ }^{56,57}$ which activates the terminal 


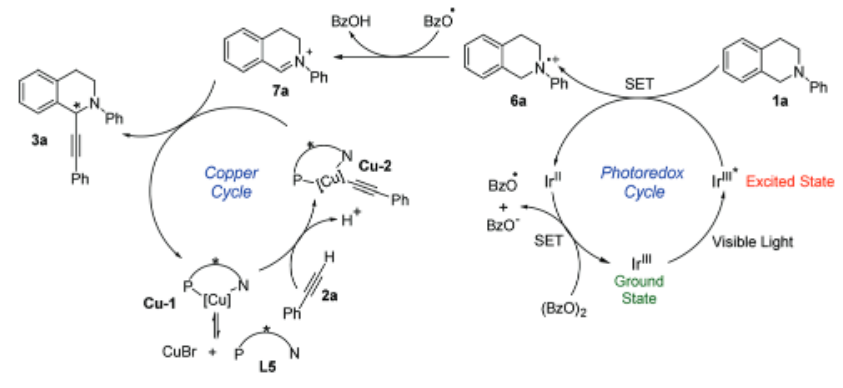

Scheme 2 Proposed mechanism.

alkyne (2a, Scheme 2) to form a chiral Cu-QUINAP-acetylide species (Cu-2) ${ }^{56,57}$ Addition of nucleophilic, chiral acetylide (Cu-2) to electrophilic 7a results in the formation of optically active 1-alkynyl tetrahydroisoquinoline (3a). ${ }^{9,27}$

\section{Conclusions}

In summary, herein we report the first example of a highly efficient asymmetric cross-dehydrogenative-coupling reaction between tertiary amines and terminal alkynes. Synergistic photocatalytic and copper-catalyzed cycles cooperate to yield optically active 1-alkynyl tetrahydroisoquinolines in good yields (up to 90\%) and excellent enantioselectivities (up to $96 \%)$. With $N$-aryl-tetrahydroisoquinolines as a 'proof-ofconcept' substrate, we believe that this method can become a general approach to optically active propargylic amines. This combination of a photocatalyst and chiral copper catalysis provides an excellent low temperature alternate to the $\mathrm{A}^{3}$ coupling reactions developed by $\mathrm{us}^{58}$ and others ${ }^{59,60}$ to produce chiral propargylic amines. Low photocatalyst loading $(1 \mathrm{~mol}$ $\%)$, the convenience of using visible light, and avoiding prefunctionalization of the starting material firmly place this reaction in the green chemist's synthetic toolbox.

\section{Acknowledgements}

We are grateful to the Canada Research Chair (Tier 1) Foundation (to C.-J.L.), the FQRNT, NSERC and CFI for their support of our research. We thank Professor Eli ZysmanColman (Department of Chemistry, University of St. Andrews, United Kingdom) for providing samples of the photoredox catalysts.

\section{Notes and references}

1 C. Zheng and S.-L. You, RSC Adv., 2014, 4, 6173-6214.

2 Y. Wu, J. Wang, F. Mao and F. Y. Kwong, Chem. - Asian J., 2014, 9, 26-47.

3 S. A. Girard, T. Knauber and C.-J. Li, Angew. Chem., Int. Ed., 2014, 53, 74-100.
4 M. Zhang and A. Zhang, J. Heterocycl. Chem., 2012, 49, 721725.

5 C. S. Yeung and V. M. Dong, Chem. Rev., 2011, 111, 12151292.

6 M. Klussmann and D. Sureshkumar, Synthesis, 2011, 353-369.

7 C. J. Scheuermann, Chem. -Asian J., 2010, 5, 436-451.

8 C.-J. Li, Acc. Chem. Res., 2009, 42, 335-344.

9 Z. Li and C.-J. Li, J. Am. Chem. Soc., 2004, 126, 1181011811.

10 Z. Li, D. S. Bohle and C.-J. Li, Proc. Natl. Acad. Sci. U. S. A., 2006, 103, 8928-8933.

11 Z. Li and C.-J. Li, J. Am. Chem. Soc., 2006, 128, 56-57.

12 Y. Zhang and C.-J. Li, Angew. Chem., Int. Ed., 2006, 45, 1949-1952.

13 Y. Zhang and C.-J. Li, J. Am. Chem. Soc., 2006, 128, 42424243.

14 Z. Li, L. Cao and C.-J. Li, Angew. Chem., Int. Ed., 2007, 46, 6505-6507.

15 L. Zhao and C.-J. Li, Angew. Chem., Int. Ed., 2008, 47, 70757078.

16 P. Wang, H. Rao, R. Hua and C.-J. Li, Org. Lett., 2012, 14, 902-905.

17 M. V. Leskinen, Á. Madarász, K.-T. Yip, A. Vuorinen, I. Pápai, A. J. Neuvonen and P. M. Pihko, J. Am. Chem. Soc., 2014, 136, 6453-6462.

18 Q.-Y. Meng, J.-J. Zhong, Q. Liu, X.-W. Gao, H.-H. Zhang, T. Lei, Z.-J. Li, K. Feng, B. Chen, C.-H. Tung and L.-Z. Wu, J. Am. Chem. Soc., 2013, 135, 19052-19055.

19 G. Li, S. Qian, C. Wang and J. You, Angew. Chem., Int. Ed., 2013, 52, 7837-7840.

20 G. Zhang, Y. Ma, S. Wang, W. Kong and R. Wang, Chem. Sci., 2013, 4, 2645-2651.

21 R. Y. Nimje, M. V. Leskinen and P. M. Pihko, Angew. Chem., Int. Ed., 2013, 52, 4818-4822.

22 A. P. Antonchick and L. Burgmann, Angew. Chem., Int. Ed., 2013, 52, 3267-3271.

23 D. F. Havey and D. M. Sigano, J. Org. Chem., 1996, 61, 2268-2272.

24 J. J. A. Porco, F. J. Schoenen, T. J. Stout, J. Clardy and S. L. Schreiber, J. Am. Chem. Soc., 1990, 112, 7410-7411.

25 A. Hoepping, K. M. Johnson, C. George, J. FlippenAnderson and A. P. Kozikowski, J. Med. Chem., 2000, 43, 2064-2071.

26 C. Swithenbank, P. J. McNulty and K. L. Viste, J. Agric. Food Chem., 1971, 19, 417-421.

27 Z. Li, P. D. MacLeod and C.-J. Li, Tetrahedron: Asymmetry, 2006, 17, 590-597.

28 Z. Li and C.-J. Li, Org. Lett., 2004, 6, 4997-4999.

29 M. Chrzanowska and M. D. Rozwadowska, Chem. Rev., 2004, 104, 3341-3370.

30 J. Yu, Z. Li, K. Jia, Z. Jiang, M. Liu and W. Su, Tetrahedron Lett., 2013, 54, 2006-2009.

31 H. Buschmann, H.-D. Scharf, N. Hoffmann and P. Esser, Angew. Chem., Int. Ed. Engl., 1991, 30, 477-515.

32 D. A. Nicewicz and D. W. C. MacMillan, Science, 2008, 322, 77-80. 
33 D. A. Nagib, M. E. Scott and D. W. C. MacMillan, J. Am. Chem. Soc., 2009, 131, 10875-10877.

34 J. M. R. Narayanam and C. R. J. Stephenson, Chem. Soc. Rev., 2011, 40, 102-113.

35 J. M. R. Narayanam, J. W. Tucker and C. R. Stephenson, J. Am. Chem. Soc., 2009, 131, 8756-8757.

36 D. Kalyani, K. B. McMurtrey, S. R. Neufeldt and M. S. Sanford, J. Am. Chem. Soc., 2011, 133, 18566-18569.

37 M. S. Sanford and Y. Ye, J. Am. Chem. Soc., 2012, 134, 90349037.

38 T. P. Yoon, M. A. Ischay and J. Du, Nat. Chem., 2010, 2, 527-532.

39 M. A. Ischay, M. E. Anzovino, J. Du and T. P. Yoon, J. Am. Chem. Soc., 2008, 130, 12886-12887.

40 J. Du, K. L. Skubi, D. M. Schultz and T. P. Yoon, Science, 2014, 344, 392-396.

41 M. Rueping, R. M. Koenigs, K. Poscharny, D. C. Fabry, D. Leonori and C. Vila, Chem. - Eur. J., 2012, 18, 5170-5174.

42 A. G. Condie, J. C. González-Gómez and C. R. J. Stephenson, J. Am. Chem. Soc., 2010, 132, 1464-1465.

43 M. Rueping, S. Zhu and R. M. Koenigs, Chem. Commun., 2011, 47, 12709-12711.

44 E. Sauvageot, R. Marion, F. Sguerra, A. Grimault, R. Daniellou, M. Hamel, S. Gaillard and J.-L. Renaud, Org. Chem. Front., 2014, 1, 639-644.

45 Y. Pan, S. Wang, C. W. Kee, E. Dubuisson, Y. Yang, K. P. Loh and C.-H. Tan, Green Chem., 2011, 13, 3341-3344. 46 D. P. Hari and B. König, Org. Lett., 2011, 13, 3852-3855.
47 Y. Pan, C. W. Kee, L. Chen and C.-H. Tan, Green Chem., 2011, 13, 2682-2685.

48 Z. Zuo, D. Ahneman, L. Chu, J. Terrett, A. G. Doyle and D. W. C. MacMillan, Science, 2014, 345, 437-440.

49 D. A. DiRocco and T. Rovis, J. Am. Chem. Soc., 2012, 134, 8094-8097.

50 G. Bergonzini, C. S. Schindler, C.-J. Wallentin, E. N. Jacobsen and C. R. J. Stephenson, Chem. Sci., 2014, 5, 112-116.

51 H. H. Morgan, J. Chem. Soc., 1923, 123, 2901-2907.

52 A. Alexakis and C. Benhaim, Eur. J. Org. Chem., 2002, 32213236.

53 J.-J. Zhong, Q.-Y. Meng, G.-X. Wang, Q. Liu, B. Chen, K. Feng, C.-H. Tung and L.-Z. Wu, Chem. - Eur. J., 2013, 19, 6443-6450.

54 E. Boess, C. Schmitz and M. Klussmann, J. Am. Chem. Soc., 2012, 134, 5317-5325.

55 K. Tokumaru, Res. Chem. Intermed., 1996, 22, 255-273.

56 C. Koradin, N. Gommermann, K. Polborn and P. Knochel, Chem. - Eur. J., 2003, 9, 2797-2811.

57 C. Koradin, K. Polborn and P. Knochel, Angew. Chem., Int. Ed., 2002, 41, 2535-2538.

58 W.-J. Yoo, L. Zhao and C.-J. Li, Aldrichimica Acta, 2011, 44, 43-51.

59 V. A. Peshkov, O. P. Pereshivko and E. V. V. d. Eycken, Chem. Soc. Rev., 2012, 41, 3790-3807.

60 W. Lin, T. Cao, W. Fan, Y. Han, J. Kuang, H. Luo, B. Miao, X. Tang, Q. Yu, W. Yuan, J. Zhang, C. Zhu and S. Ma, Angew. Chem., Int. Ed., 2014, 53, 277-281. 